\title{
On the scaling characteristics of observed and simulated spatial soil moisture fields
}

\author{
M. Gebremichael ${ }^{1}$, R. Rigon ${ }^{2}$, G. Bertoldi ${ }^{3}$, and T. M. Over ${ }^{4}$ \\ ${ }^{1}$ Department of Civil and Environmental Engineering, University of Connecticut, Storrs, CT 06269, USA \\ ${ }^{2}$ Dipartimento di Ingegneria Civile e Ambientale/CUDAM, Universitá di Trento, Via Mesiano, 77, 38050 Trento, Italia \\ ${ }^{3}$ Institute for Alpine Environment, EURAC research, Viale Druso 1, 39100 Bolzano, Italia \\ ${ }^{4}$ Department of Geology/Geography, Eastern Illinois University, 600 Lincoln Ave., Charleston, IL 61920-3099, USA
}

Received: 31 January 2008 - Revised: 27 November 2008 - Accepted: 9 December 2008 - Published: 25 February 2009

\begin{abstract}
By providing continuous high-resolution simulations of soil moisture fields, distributed hydrologic models could be powerful tools to advance the scientific community's understanding of the space-time variability and scaling characteristics of soil moisture fields. However, in order to use the soil moisture simulations from hydrologic models with confidence, it is important to understand whether the models are able to represent in a reliable way the processes regulating soil moisture variability. In this study, a comparison of the scaling characteristics of spatial soil moisture fields derived from a set of microwave radiometer observations from the Southern Great Plains 1997 experiment and corresponding simulations using the distributed hydrologic model GEOtop is performed through the use of generalized variograms. Microwave observations and model simulations are in agreement with respect to suggesting the existence of a scale-invariance property in the variograms of spatial soil moisture fields, and indicating that the scaling characteristics vary with changes in the spatial average soil water content. However, observations and simulations give contradictory results regarding the relationship between the scaling parameters (i.e. spatial organization) and average soil water content. The drying process increased the spatial correlation of the microwave observations at both short and long separation distances while increasing the rate of decay of correlation with distance. The effect of drying on the spatial correlation of the model simulations was more complex, depending on the storm and the simulation examined, but for the largest storm in the simulation most similar to the observations, drying increased the long-range correlation but decreased the
\end{abstract}

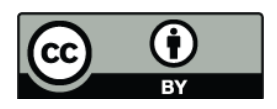

Correspondence to: $\mathrm{M}$. Gebremichael (mekonnen@engr.uconn.edu) short-range. This is an indication that model simulations, while reproducing correctly the total streamflow at the outlet of the watershed, may not accurately reproduce the runoff production mechanisms. Consideration of the scaling characteristics of spatial soil moisture fields can therefore serve as a more intensive means for validating distributed hydrologic models, compared to the traditional approach of only comparing the streamflow hydrographs.

\section{Introduction}

Near-surface soil moisture is an important variable that influences atmospheric, hydrologic, and biogeochemical processes over a wide range of scales. Ignoring the small-scale variability of soil moisture fields could lead to large errors in applications (e.g. Nykanen and Foufoula-Georgiou, 2001). Characterizing the spatial pattern of soil moisture variability is also important to provide quantitative confidence to the current Aqua-AMSR (Njoku et al., 2003) and planned SMOS (Silvestrin et al., 2001) satellite soil moisture products.

Based on limited number of soil moisture images derived from short-term aircraft-based microwave observations, several studies have shown the existence of scale-invariance properties in the spatial soil moisture fields (e.g. RodriguezIturbe et al., 1995; Hu et al., 1997; Nykanen and FoufoulaGeorgiou, 2001; Oldak et al., 2002; Das and Mohanty, 2008). The implication of scale-invariance is that only a few parameters ( 2 to 3 ) are required to transform spatial soil moisture fields between different scales. The practical feasibility of this approach hinges on the ability to estimate the scaling parameters from large-scale observables, and this remains the stumbling block preventing the scientific community from

Published by Copernicus Publications on behalf of the European Geosciences Union and the American Geophysical Union. 
using this approach to downscale spatial soil moisture fields. More research is needed to examine the temporal evolution of the scaling parameters and to establish linkages with physical factors and processes (e.g. Albertson and Montaldo, 2003). Identifying the capability of a hydrological model to accurately represent soil moisture scaling would also serve as a means of model testing in order to provide confidence in the simulated spatial patterns.

Distributed hydrologic models can be powerful tools for such scaling investigations by virtue of their ability to simulate continuous, high-resolution, soil moisture fields. In a recent study, Manfreda et al. (2007) investigated the scaling characteristics of spatial soil moisture fields simulated with the variable infiltration capacity (VIC) (Nijssen et al., 1997) hydrologic model over the southern Great Plains region by examining the variance of spatial averages at different resolutions from $0.125^{\circ}$ to $1.0^{\circ}$, and reported the following results: (i) variance of spatial soil moisture fields in the top $10 \mathrm{~cm}$ and top $100 \mathrm{~cm}$ exhibit scale-invariance; (ii) the drying process tends to reduce the spatial correlation of the soil moisture; and (iii) changes in the scaling parameter values are controlled not only by the mean value of the process but also by the different dynamics of the wetting and drying cycles.

With distributed hydrologic models, it is possible to perform such investigations and advance our understanding of the scaling properties of soil moisture fields. However to use the hydrologic models with confidence, it is important to understand whether the models are able to represent in a reliable way the processes regulating soil moisture variability. So far, there is only little work done to compare the scaling properties of simulated soil moisture fields to observations (Dubayah et al., 1997; Peters-Lidard et al., 2001). Thus, it is worth exploring in detail how distributed hydrologic models perform in retrieving observed scaling parameters.

This paper is a contribution towards filling this gap. For this study, we chose the GEOtop hydrologic model (Rigon et al., 2006) because it is a process-based model that integrates the 3-D Richards Equation. Specifically, we seek to understand how well GEOtop can simulate the observed scaling properties of spatial soil moisture fields obtained from remote sensing observations. We will also investigate how much the initialization scheme and data resolutions affect the results. We take advantage of the soil moisture estimates made using aircraft-based imagery from the Southern Great Plains 1997 (SGP97) Hydrology Experiment (Jackson, 1997) for validation of simulation results. The case study takes place from 27 June to 16 July and encompasses both wetting and drying cycles in order to observe the performance of GEOtop under both conditions and to test its ability to make a transition from one to the other. In particular, we investigate if the observed and simulated moisture fields exhibit scale invariance in their generalized variograms, and to analyze the relationship between the scaling parameters and spatial average soil water content.

\section{Study region and data}

\subsection{Study region}

Our study region is the Little Washita watershed located in the southwest Oklahoma in the Southern Great Plains region of the USA. The watershed, which has a drainage area of $602 \mathrm{~km}^{2}$ upstream of the USGS stream gauge 07327550 near Ninnekah, OK, is operated as an experimental watershed by the US Department of Agriculture - Agricultural Research Service. As a result, it is well-instrumented for hydrological studies and has been the site for several major soil moisture field experiments. We chose to study the Little Washita watershed because of its dense network of meteorological sites and soil moisture fields from aircraft-based imagery to force simulations and evaluate model performance. The study period spans from 27 June to 16 July 1997, which encompasses two dry-down periods interrupted on 11 July by a convective storm with a basin averaged daily precipitation of $53 \mathrm{~mm}$, an amount comparable to the average monthly rainfall in July of $56.4 \mathrm{~mm}$ (Allen and Naney, 1991). The topography of the region is gently rolling, changing about $10 \mathrm{~m}$ per kilometers, with no major orographic features. In general, the soils are well-drained loams and sands, $1-2 \mathrm{~m}$ in depth, and overlie sandstone and shale bedrock (Allen and Naney, 1991). The soil texture is dominated by silty loam in the western and eastern parts, and by sandy soils in the central part. Land use is dominated by agriculture and rangeland (63\%), with significant areas of winter wheat and other crops concentrated in the floodplain and western portions of the watershed area. Figure 1 shows the topography derived from a 30-m USGS NED digital elevation model dataset, soil texture obtained from Mohanty et al. (2002), and land cover obtained from Goddard Earth Sciences Data and Information Services Center.

\subsection{Observations}

The Southern Great Plains 1997 Hydrology Experiment (SGP97) (Jackson et al., 1999) was a cooperative effort between NASA, USDA, and several other government agencies and universities conducted with the primary goal of collecting a time series of spatial soil moisture data. The core of the experiment involved the deployment of the L-band electronically scanned thinned array radiometer (ESTAR) for daily mapping of surface soil moisture. ESTAR is a synthetic aperture, passive microwave radiometer operating at a frequency of $1.413 \mathrm{GHz}(21 \mathrm{~cm})$. ESTAR was flown on a P-3B aircraft (at an altitude of $7.5 \mathrm{~km}$ ) operated by the NASA Wallops Flight Facility. The P-3B flew over Little Washita at approximately 16:00 UTC (10:00 CST). The footprint of the raw brightness temperature data is $400 \mathrm{~m}$, but the raw data were resampled to a pixel grid size of $800 \mathrm{~m} \times 800 \mathrm{~m}$ to derive moisture maps that are representative of the top $5 \mathrm{~cm}$ of soil (e.g. Famiglietti et al., 1999). Further details on the ESTAR 
instrument and the inversion of ESTAR brightness temperatures to volumetric soil moisture can be found in LeVine et al. (1994), Jackson et al. (1995), Jackson and LeVine (1996), and Jackson et al. (1999). ESTAR-derived soil moisture estimates were found to be within 3\% of estimates of volumetric soil moisture from SGP97 ground samples (Jackson et al., 1999).

These ESTAR-based spatially-distributed soil moisture estimates, available at http://daac.gsfc.nasa.gov/fieldexp/ SGP97/estar (verified October 2007), were used in this study. The estimates cover a large strip of approximately $50 \mathrm{~km}$ (West-East) by $250 \mathrm{~km}$ (North-South), and we selected a subset of this strip covering Little Washita. We converted the original data expressed as absolute volumetric soil moisture to relative soil moisture by dividing by the effective soil porosity of the characteristic soil of the pixel. The texture-dependent porosity values were obtained from from Rawls et al. (1982), consistent with the approach followed by Rodriguez-Iturbe et al. (1995) for their soil moisture scaling investigations.

\subsection{Numerical model}

GEOtop is a fully-distributed process-based hydrologic model (Rigon et al., 2006). Its capabilities include simulation of the following: (i) both water and energy budgets, (ii) radiation budget in complex topography, (iii) surface runoff by kinematic wave, (iv) subsurface soil water processes by integration of the 3-D Richards Equation (and, as a consequence, saturation excess and infiltration excess runoff capabilities), (v) multi-layer snow cover, (vi) forecasted surface and subsurface temperatures, (vii) sensible and latent heat transfer by the Monin-Obukhov scheme, and (viii) dependence of hydraulic soil characteristics on temperature.

The GEOtop model showed good skill in reproducing the point-wise energy and water balance and the streamflow hydrograph during SGP97 (Rigon et al., 2006; Bertoldi et al., 2006). Two sets of daily-average near-surface $(5 \mathrm{~cm})$ relative soil moisture content maps over the Little Washita watershed simulated using the GEOtop model were made available for this study. The difference between the two sets of maps was caused by differences in the initialization schemes of the corresponding simulation. One simulation, the short-term one, was performed for the 21-day period from 26 June to 16 July 1997 , forced by a dense network of 42 rain gauges, and using the ESTAR-observed soil moisture distribution as the initial condition. The other simulation was performed for the whole calendar year 1997, with calibration parameters identical to those used in the first simulation, but with fewer rain gauges. In this second long-term simulation, at the beginning of the study period (26 June), the modeled surface soil moisture distribution has presumably lost memory of the initial condition. Having both these simulations made it possible to consider the effect of initialization schemes on the results. Both simulations used a 1-h time step and 200-m horizontal
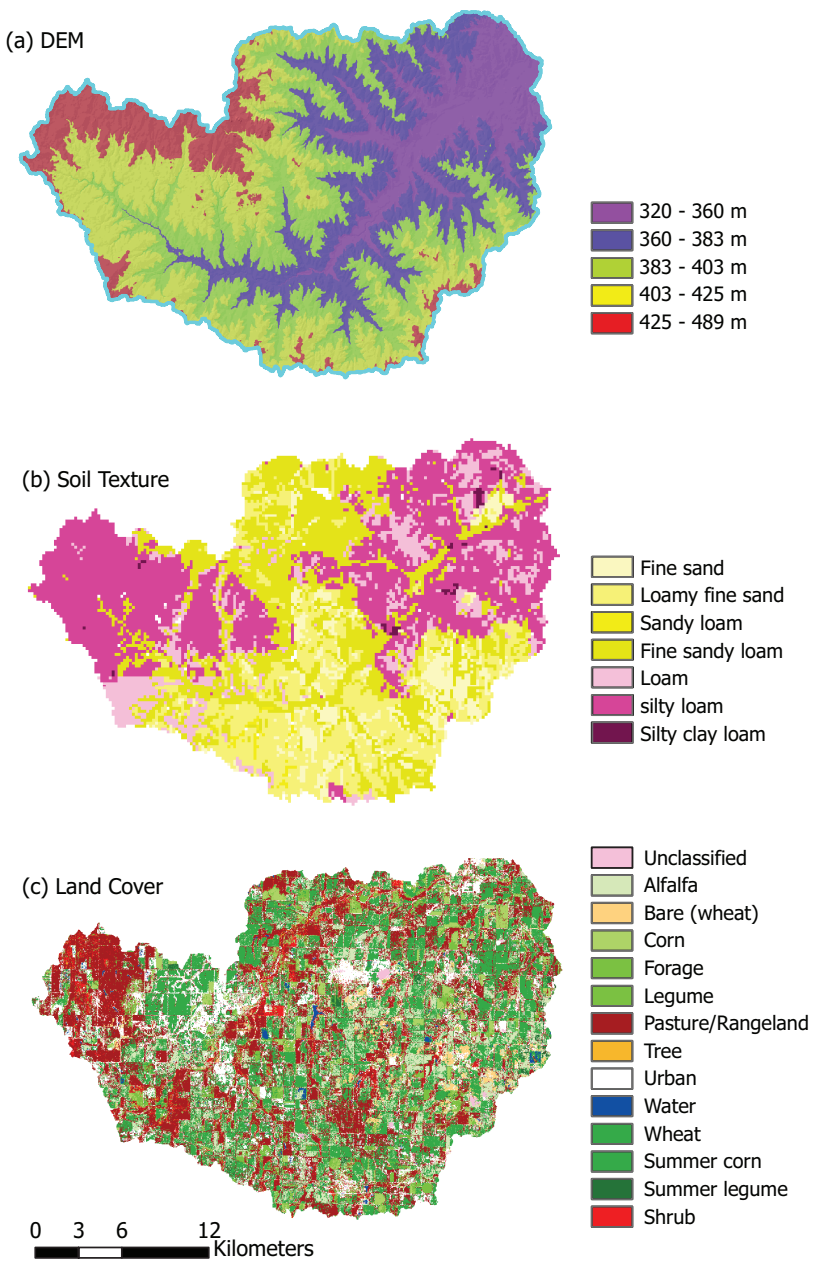

Fig. 1. Little Washita watershed properties: (a) digital elevation model, (b) soil texture, and (c) land use.

resolution. The simulations were aggregated to $800-\mathrm{m}$ resolution to match the ESTAR resolution, and below we discuss the effect of this aggregation.

\section{Spatial scaling analysis}

The scaling characteristics of a geophysical field can be studied in several ways. Most soil moisture scaling analyses examine the variance of spatial averages at different resolutions. This approach, however, requires a large number of spatial data, and is thus suitable only for sufficiently large areas and/or data of high resolution. To overcome this problem in the relatively small Little Washita watershed, we have employed the generalized variogram method. The $q$ th moment of a generalized variogram, $C_{q}(\lambda)$, is defined as (Yaglom, 1987)

$C_{q}(\lambda)=\left\langle|z(x)-z(x+r)|^{q}\right\rangle$ 


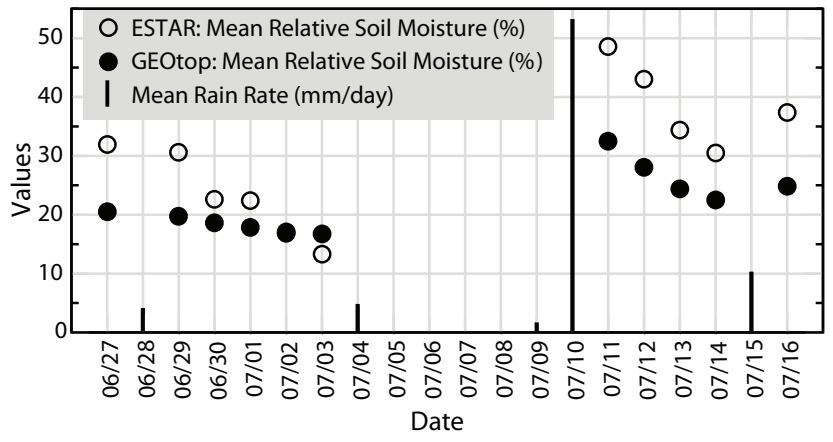

Fig. 2. Time series of watershed-scale mean relative soil moisture (from ESTAR observations and GEOtop simulations) and mean daily rain rate (from a dense network of rain gauges) for the Little Washita watershed from 27 June to 16 July 1997.

where $|r|=\lambda$ is the separation distance, $z(x)$ is the value of the field being analyzed at location $x$, and $<>$ is the ensemble averaging operator. The definition of $C_{q}(\lambda)$ assumes that the random field of the soil moisture differences is stationary, because the $q$ th moment is supposed to depend only on the separation distance. This assumption is often made in most practical applications.

The $q$ th moment $C_{q}(\lambda)$ of the generalized variogram is said to be scaling if the following relation holds:

$C_{q}(\lambda)=\lambda^{K(q)} C_{q}(1) \propto \lambda^{K(q)}$.

We estimated the scaling exponent (or scaling parameter) $K(q)$ after logarithmically transforming this equation. For both the ESTAR estimates and the GEOtop simulations coarse-grained to $800 \mathrm{~m}$, we considered separation distances ranging from $0.8 \mathrm{~km}$ to $10.4 \mathrm{~km}$. The total number of pairs of soil moisture data used ranges from 1984 at a separation distance of $0.8 \mathrm{~km}$ to 1216 at $10.4 \mathrm{~km}$. We examined the scaling properties of the following four spatial soil moisture datasets: (1) the ESTAR estimates at $800 \mathrm{~m}$ resolution, (2) the shortterm GEOtop simulation coarse-grained to $800 \mathrm{~m}$ resolution, (3) the long-term GEOtop simulation coarse-grained to $800 \mathrm{~m}$ resolution, and (4) the short-term GEOtop simulation at the model resolution of $200 \mathrm{~m}$.

The results of this analysis will be presented below in terms of two parameters characterizing the variogram, $C_{q=1}(\lambda=0.8 \mathrm{~km})$, a measure of short-range variability, and $K(q=1)$, the slope of the fitted variogram power-law. The physical interpretation of these parameters is as follows. First, one expects that the variogram will increase with separation distance, at least for small separation distances. The rate at which the variogram increases with separation distance is a measure of the organization or spatial structure of the soil moisture field. For a nearly uncorrelated field, increasing separation distance beyond some small positive value will have an insignificant effect on the variogram, giving a more or less constant but large value of $C_{1}(\lambda)$ indepen- dent of separation distance, and therefore small $K(q)$ values. At the opposite extreme, a nearly uniform field will have small but again more or less constant $C_{1}(\lambda)$ values, and therefore again a small $K(q)$ value. However, a field with correlation that continuously decreases with separation distance exhibits small variogram values for small separation distances (because nearby points are likely to be very similar in magnitude) but increasing differences in field values $z(x)$ as separation distance is increased, causing a continuous rise in the plot of the variogram versus separation distance, and therefore high $K(q)$ values. The particular value $K(q)$ takes is an indicator of the rate at which the correlation decreases with separation distance.

\section{Results and discussion}

\subsection{Watershed-averaged soil moisture}

Figure 2 compares the time series watershed-averaged relative soil moisture values obtained from ESTAR observations and the short-term GEOtop simulations on the days when the ESTAR estimates are available. Superimposed in the figure is the corresponding spatial mean of daily rainfall obtained from the dense network of 42 rain gauges. The ESTAR spatial mean relative soil moisture (r.s.m.) during the study period encompasses four different trends: (i) an initially-dry dry-down period (29 June-10 July, ESTAR mean r.s.m. decreases from $31 \%$ to $13 \%$ spatial mean r.s.m.), (ii) a strong increase in wetness (10 July-11 July, with $53 \mathrm{~mm}$ of rainfall, and ESTAR mean r.s.m. of 49\%), (iii) an initially-wet dry-down period (11 July-14 July, ESTAR mean r.s.m. from $49 \%$ to $31 \%$ ), and (iv) a mild increase in wetness (14 July vs. 16 July, when, following a mild storm, ESTAR mean r.s.m. increases to $37 \%$ ).

We note that soil moisture estimates from both the ESTAR observations and the GEOtop simulations responded to temporal rainfall fluctuations (i.e. spatial mean soil moisture content increases following storms, and decreases during dry-downs), suggesting that both ESTAR observations and GEOtop simulations represented realistic patterns of temporal variability of soil moisture at the watershed-scale. The correlation between the time-series of spatial mean ESTAR observations and GEOtop simulations was 0.95 , confirming agreement in temporal fluctuation behavior. However, for most of the days when ESTAR-observed spatial mean exceeded $20 \%$ r.s.m., the simulated soils were drier than ESTAR-observed soils, and the magnitude of this discrepancy increased with the wetness level. For the driest day (i.e. ESTAR-observed spatial mean of $13 \%$ r.s.m.), the simulated soils were wetter than ESTAR-observed soils.

\subsection{Scaling}

Figure 3 shows the variograms and best-fit lines of logs of the generalized variograms $C_{1}(\lambda), C_{2}(\lambda)$, and $C_{4}(\lambda)$, as a 
July 11
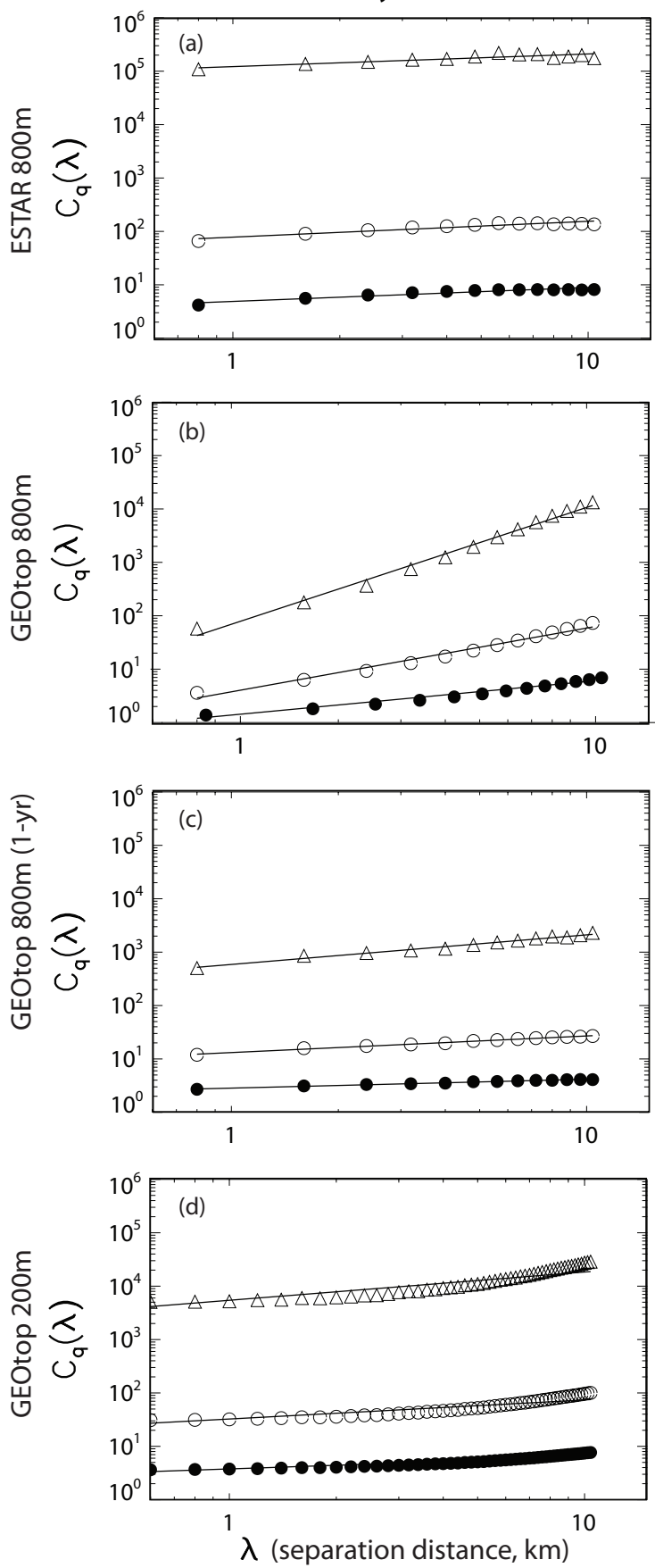

July 14
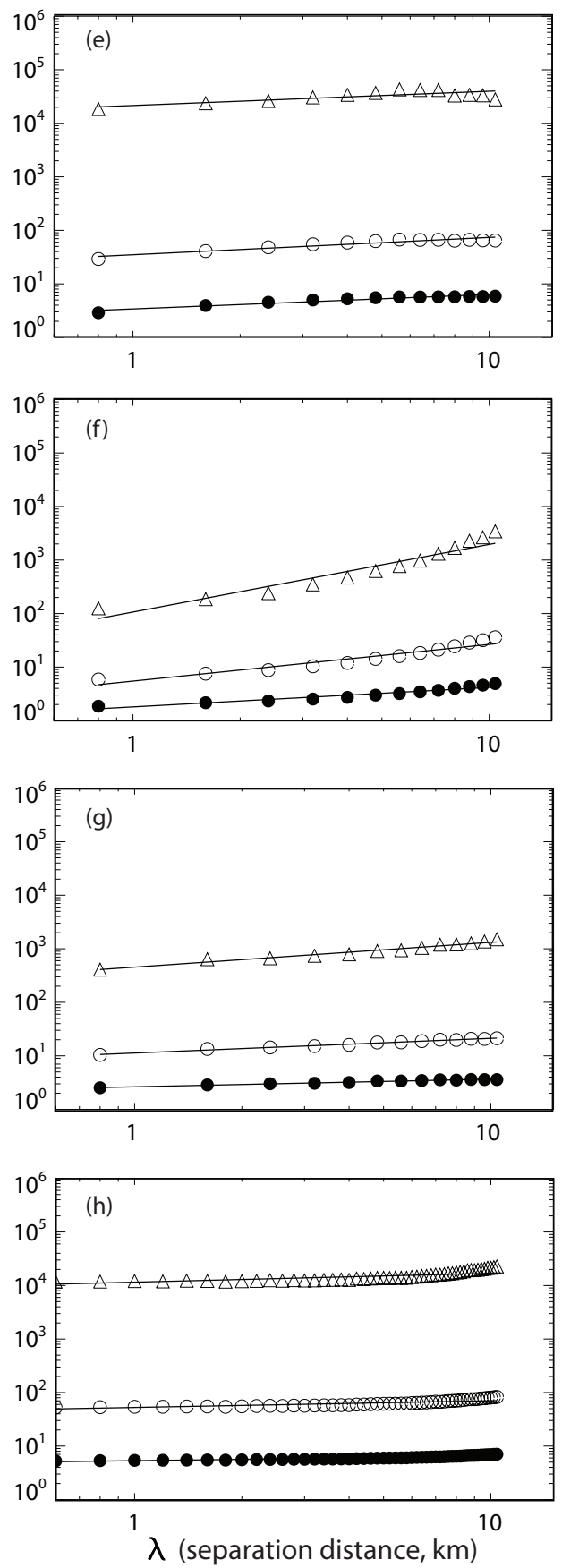

Fig. 3. Generalized variograms (for moment orders of 1,2 and 4, bottom, middle and top, respectively in each plot) of the spatial soil moisture fields derived from (a), (e) ESTAR observations, (b), (f) short-term GEOtop simulations coarse-grained to $800 \mathrm{~m}$ resolution, (c), (g) long-term GEOtop simulations coarse-grained to $800 \mathrm{~m}$ resolution, and (d), (h) short-term GEOtop simulations at model resolution of $200 \mathrm{~m}$. Left panels (a, b, c, d) represent results for the wet day (11 July) following the 10 July storm, and right panels (e, f, g, h) represent results for the drier day (14 July) four days after the storm.

function of $\log \lambda$, for 11 July (wet surface soil following the strong storm on 10 July) and 14 July (drier surface soil four days after the storm), derived from ESTAR observations and various GEOtop simulations. Approximate linear- ity in the $\log -\log$ dependency of $C_{1}(\lambda), C_{2}(\lambda)$, and $C_{4}(\lambda)$ on separation distance can be observed in ESTAR observations and various GEOtop simulations whether the soil is wet or dry, suggesting that spatial soil moisture fields are generally 


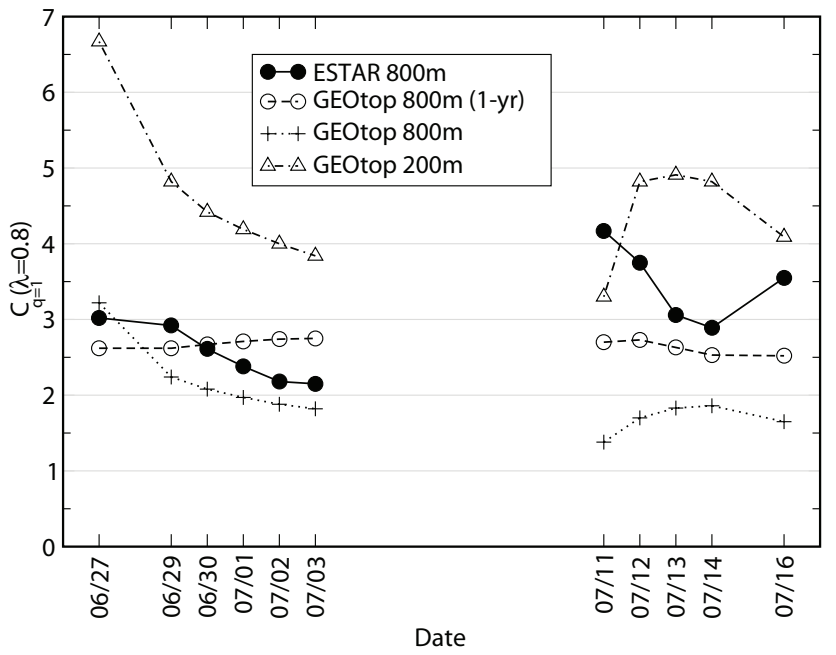

Fig. 4. Time series of generalized variogram values $C_{q=1}(\lambda=0.8 \mathrm{~km})$ derived from ESTAR observations and various GEOtop simulations.

scale-invariant in separation distances that range from, 0.8 to $10.4 \mathrm{~km}$; both observed and simulated fields continue to encounter variability throughout this range of scales. This result is consistent with previous findings (e.g. RodriguezIturbe et al., 1995; Hu et al., 1997; Oldak et al., 2002). However, we note differences in the temporal fluctuation of the slopes and intercepts of the log-log relationships among the observations and simulations; these differences are described in the sections below.

\subsection{Variability at a separation distance of $0.8 \mathrm{~km}$}

Figure 4 presents the time series of the variogram $C_{q=1}(\lambda=0.8 \mathrm{~km})$, a proxy for the intercept parameter, derived from ESTAR observations and various GEOtop simulations. During the dry-down periods (29 June-3 July and 1114 July), ESTAR's $C_{1}(0.8)$ values progressively decrease, indicating that the short-range variability decreased as the soils dried. The variability increases following the rain events on 10 July and 15 July. The picture that emerges from this analysis is that the short-range variability of ESTAR observations is strongly tied to the mean soil moisture content, and that the spatial soil moisture field becomes more variable for wet conditions. This behavior is consistent with observations in humid areas (e.g. Bell et al., 1980; Famiglietti et al., 1999).

Let us now examine the short-term GEOtop simulation coarse-grained to $800 \mathrm{~m}$ (denoted "GEOtop $800 \mathrm{~m}$ " in the figure). GEOtop's $C_{1}(0.8)$ values are smaller overall than the corresponding ESTAR values, indicating that the simulations had less short-range spatial variability than those of the observations. During the initially-dry dry-down period (29 June-3 July), GEOtop's $C_{1}(0.8)$ values decreased as the soils dried, indicating that the simulations had less shortrange variability for dry conditions when the GEOtop's spa- tial mean soil moisture content was within the range of $20 \%$ r.s.m. to $17 \%$ r.s.m., a behaviour consistent with ESTAR observations. However, during the initially-wet dry-down period (11-14 July) when GEOtop's spatial mean soil moisture content decreased from $49 \%$ r.s.m. to $31 \%$ r.s.m., the shortrange variability increased as the soils dried, a behavior that contradicts ESTAR observations. GEOtop's variability decreases following the rain events on 10 July and 15 July, continuing the contradiction with ESTAR observations. The picture that emerges from this analysis is that (1) the relationship between GEOtop's short-range spatial variability and wetness level depends on the range of the wetness level; (2) for dry soils, the simulation's short-range variability decreases with decreasing mean water content, consistent with ESTAR observations; (3) for relatively wetter soils, the simulation's short-range variability increases with decreasing mean water content, contradicting ESTAR observations.

The GEOtop $800 \mathrm{~m}$ results discussed above were obtained using short-term simulation initialized on 26 June with input rainfall data from a dense network of 42 rain gauges. The amount and spatial variability of rainfall was therefore well-represented in the GEOtop model. However, the lack of sufficient time for model spin up might have affected the accuracy of the simulation, particularly in the early days of the simulation period. To investigate this, we have analyzed the long-term GEOtop simulation performed for the whole year of 1997, i.e. initialized on 1 January 1997. The simulation was performed using the calibrated parameters of the shortterm simulation. However, only three rain gauges had data available for the whole year; therefore the model was forced only with these three stations. The long-term GEOtop simulation results coarse-grained to $800 \mathrm{~m}$ (labeled as "GEOtop $800 \mathrm{~m}$ (1-yr)" in the figures) therefore had a longer spin-up period but suffered from a coarse representation of spatial rainfall variability. The long-term GEOtop $800 \mathrm{~m}$ simulation usually had higher short-range variability, measured by the $C_{1}(0.8)$ values, than the short-term GEOtop simulation, making it closer to ESTAR observations particularly during wet days, but its variability changed very little with mean water content, contradicting both ESTAR observations and shortterm GEOtop simulations, suggesting that the coarse spatial representation of rainfall in the model might have affected the ability of the model to reproduce the temporal dynamics between soil moisture variability and wetness level in the long-term simulation.

All the above simulation results were derived from $800 \mathrm{~m} \times 800 \mathrm{~m}$ gridded soil moisture information, which were obtained by coarse graining the $200 \mathrm{~m} \times 200 \mathrm{~m}$ model simulations. To understand the effect of coarse graining on the simulation results, we have analyzed the short-term $200 \mathrm{~m} \times 200 \mathrm{~m}$ model simulation (labeled "GEOtop $200 \mathrm{~m}$ " in the figures). The GEOtop $200 \mathrm{~m} C_{1}(0.8)$ values were higher than the corresponding GEOtop $800 \mathrm{~m}$ results, as expected from statistical theory (i.e. averaging reduces variability). However, in terms of the relationship between 


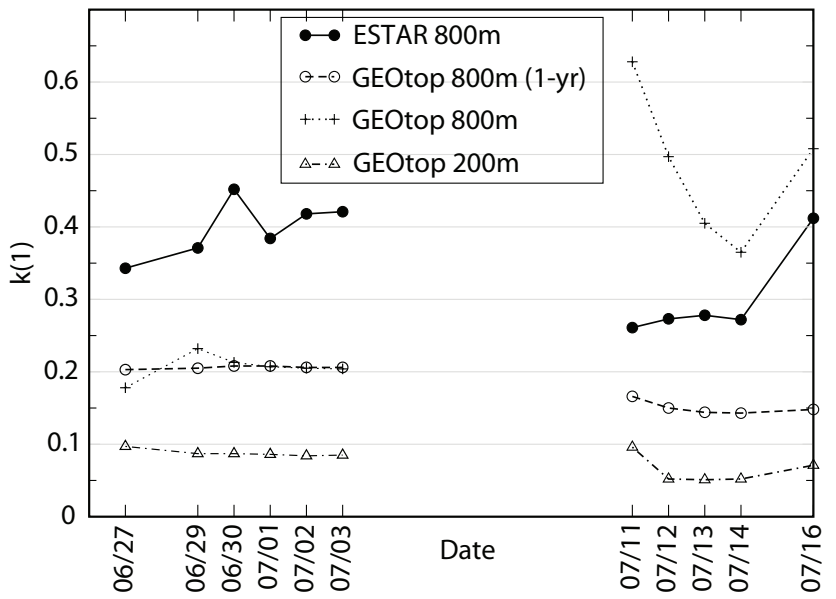

Fig. 5. Time series of generalized variogram scaling exponent $K(1)$ values derived from ESTAR observations and various GEOtop simulations.

variability and mean water content, the GEOtop $200 \mathrm{~m}$ simulation results were consistent with the GEOtop $800 \mathrm{~m}$ results (i.e. there is a high temporal correlation between $C_{1}(0.8)$ values obtained from the $200-\mathrm{m}$ and $800-\mathrm{m}$ pixel sizes), suggesting that the coarse-graining preserves the behavior of the relationship between variability and mean water content observed at the model resolution.

\subsection{Scaling parameter}

Here, we evaluate the scaling parameter $K(q=1)$ values. As discussed in Sect. 3, $K(q)$ is a measure of the rate of decrease of spatial correlation of the field: $K(q)$ values are higher for fields whose spatial correlation decreases faster with separation distance. Figure 5 presents the time series of $K(1)$ values obtained from the ESTAR observations and the various GEOtop simulations.

During the dry-down periods, ESTAR's $K(1)$ values increase slightly and the corresponding $C_{1}(0.8)$ values decrease (Fig. 4) as the soils dry, showing that the effect of dry-down on ESTAR-derived observed spatial correlation of soil moisture was to increase short-range correlation while increasing somewhat the decay of correlation with distance. However, the impact of rainfall on the rate of decay of spatial correlation seems to depend on the nature of the rainfall variability or depth. The strong storm of 10 July caused a pronounced decrease in ESTAR's rate of decay of spatial correlation with distance and a corresponding decrease in shortrange correlation (according to the large $C_{1}(0.8)$ value shown in Fig. 4), but the mild storm of 15 July caused a pronounced increase in ESTAR's rate of decay of spatial correlation but again a decrease in short-range correlation (Fig. 4), implying that long-range correlation has become much smaller.

The "GEOtop $800 \mathrm{~m}$ " (short-term) simulation gave lower $K(1)$ values prior to the 10 July storm and higher $K(1)$ val-

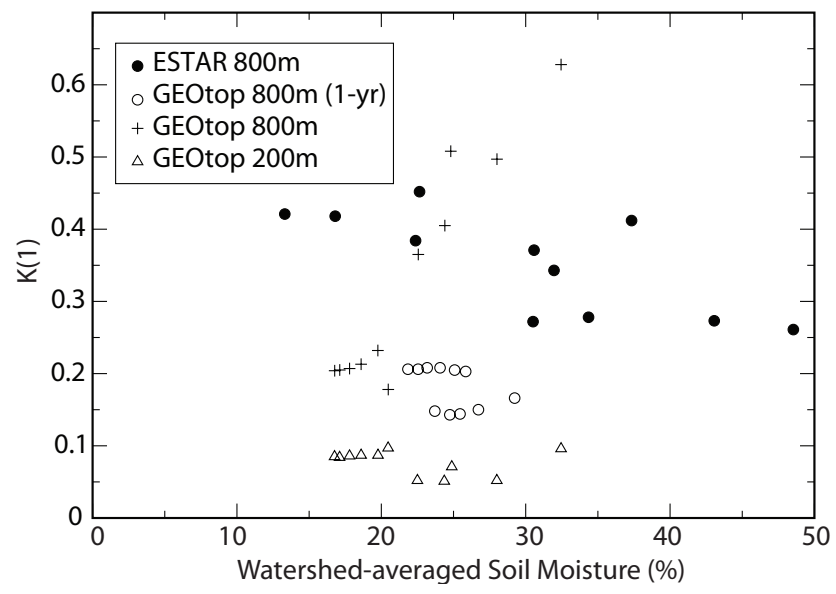

Fig. 6. Generalized variogram scaling exponent $K(1)$ as a function of watershed-averaged soil moisture content, derived from ESTAR observations and various GEOtop simulations.

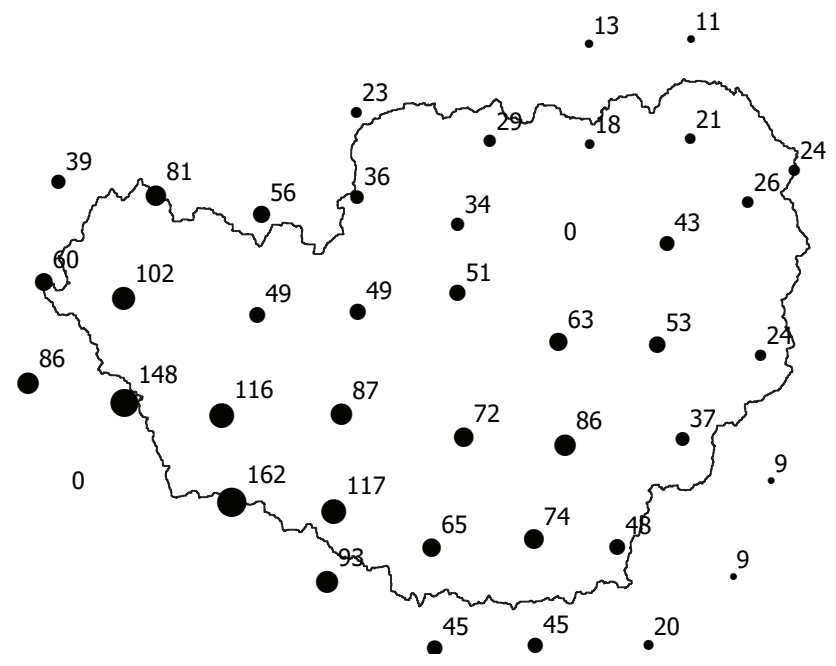

Fig. 7. Depth of rainfall total (mm) recorded on 10 July 1997, at each rain gauge location in the Little Washita watershed.

ues after the storm compared to ESTAR observations, indicating that soil moisture patterns in this GEOtop simulation and the ESTAR observations responded differently to the changes in mean water content. During the initially-wet dry-down phase (11 July-14 July), GEOtop's $K(1)$ estimates decreased dramatically with decreasing mean water content, while its $C_{1}(0.8)$ value rose from a low initial value (Fig. 4), indicating that the drying process decreased the short-range spatial correlation but increased the long-range correlation, a behavior that contradicts the ESTAR observations. The strong storm of 10 July caused an decrease in GEOtop's spatial correlation at large separation distances, contradicting ESTAR observations. The mild storm of 15 July also caused a decrease in GEOtop's long-range spatial correlation, but in the case of this storm, this is consistent with the ESTAR 
July 11

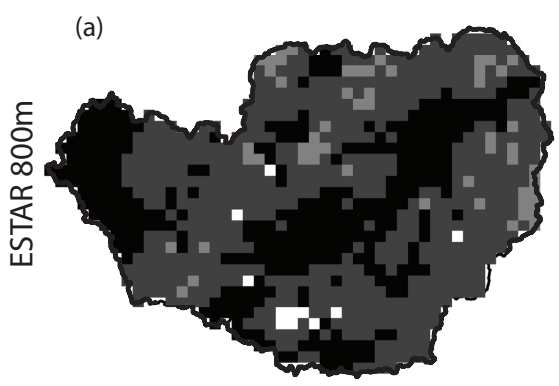

(b)

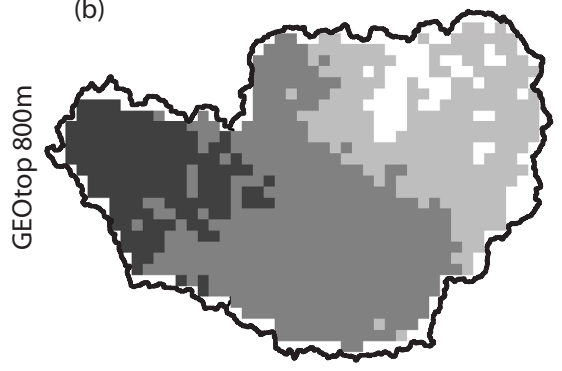

July 14

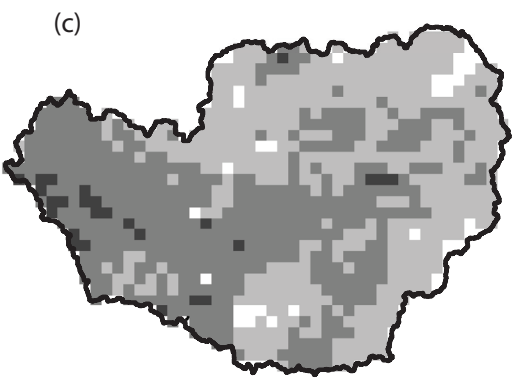

(d)

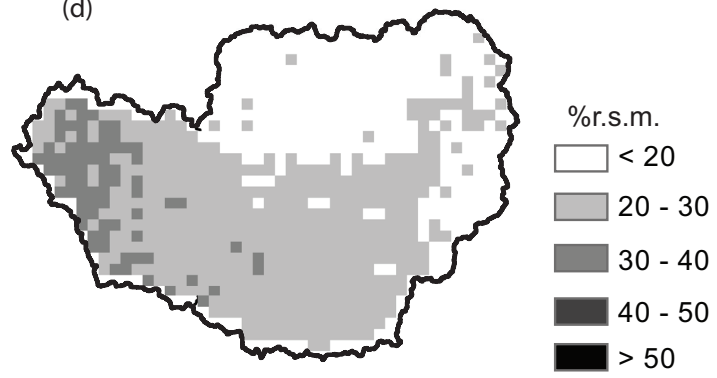

Fig. 8. Spatial maps of relative soil moisture content in the Little Washita watershed derived from (a), (c) ESTAR observations and (b), (d) short-term GEOtop simulation coarse-grained to $800 \mathrm{~m}$. Left panels (a, b) indicate results for the wet day on 11 July 1997 , following the storm on $10 \mathrm{July}$; and right panels (c, d) indicate results for the dry day on 14 July, four days after the storm.

observations. However, the ESTAR observations showed a decrease in short-range correlation (Fig. 4) while GEOtop showed a slight increase.

We have also examined how much the initialization scheme and coarse-graining affect the simulation's $K(1)$ results. The long-term simulation results show relatively little temporal variation in $K(1)$, contradicting both the ESTAR observations and the short-term GEOtop simulations, suggesting low quality of the long-term simulation with respect to soil moisture patterns, perhaps due to their coarse representation of spatial rainfall. Comparison of the shortterm "GEOtop $200 \mathrm{~m}$ " and the corresponding coarse-grained "GEOtop $800 \mathrm{~m}$ " simulation results indicate that coarsegraining preserves the dynamic relationship between simulation's $K(1)$ and mean water content, the same conclusion as was drawn from the comparison of their $C_{1}(0.8)$ values as shown in Fig. 4.

The relationship between $K(1)$ and mean water content is presented in a generalized way in Fig. 6 . The results indicate that as the soils dried, the $C_{1}(\lambda)$ curves of the ESTAR observations steepened, indicating a faster decay of correlation with separation distance, while the GEOtop simulations had the opposite behavior.

Focusing on the initially-wet dry-down period (11-14 July), let us investigate how the drying process could have induced contradictory spatial structures for observations and simulations. Figure 7 presents the spatial pattern of the 10
July daily rainfall, derived from the dense network of 42 rain gauges. The storm depths show a west-east gradient, heavier in the western part and lighter in the eastern part. The left panel of Fig. 8 presents the spatial patterns of soil moisture on 11 July following the 10 July storm, derived from ESTAR observations and the short-term 800-m GEOtop simulations. The effect of the drainage network on the spatial pattern of soil moisture is pronounced in the ESTAR observations (compare the topography shown in Fig. 1), but it is totally missing in the GEOtop simulations. This indicates that the drainage network exerted more control on the spatial variability of soil moisture pattern for ESTAR observations during wet days. On the other hand, the GEOtop simulation results are more correlated with the rainfall pattern (correlation between gauge rainfall and the corresponding GEOtop soil moisture was about 0.9 , which is significantly larger than the correlation of 0.3 between gauge rainfall and ESTAR soil moisture), indicating that the rainfall pattern exerted more control on the spatial variability of soil moisture pattern for the GEOtop simulations. The fact that ESTAR shows river-network control on soil moisture immediately after the rainfall event might be an indication that GEOtop, while reproducing correctly the total streamflow, does not reproduce so accurately the runoff production mechanism (i.e. whether it is from infiltration excess, saturation excess, and subsurface flows). It appears that the lateral re-distribution is much faster in the ESTAR observations than it is in the 
GEOtop simulation. Looking at the scaling of soil moisture can therefore be a more effective verification method for distributed hydrologic models, compared to just streamflow comparisons and visual inspections.

The right panel of Fig. 8 presents the spatial pattern of soil moisture on 14 July, after the soils dried for four days after the 10 July storm. The effect of the drainage network iss less pronounced on this dry day in the ESTAR observations, resulting in more spatially correlated ESTAR observations. However, the GEOtop simulation became less spatially correlated at short-range as the short-range smoothness in spatial soil moisture induced by the rainfall pattern is lost through inhomogeneous soil water loss mechanisms. Meanwhile, at long-range, the GEOtop simulation results became more spatially correlated as the long-range rainfall inhomogeneity decreased through drying.

\section{Conclusions}

In this study, we have evaluated the ability of a distributed hydrologic model to reproduce the scaling characteristics of observed near-surface $(5 \mathrm{~cm})$ spatial soil moisture fields. We chose the GEOtop hydrologic model because it is a processbased model that integrates the 3-D Richards Equation. We took advantage of the ESTAR microwave radiometer-based estimates of soil moisture, available for the Little Washita watershed during the SGP97 field campaign, for validation of model simulation results. We studied the scaling characteristics through the use of generalized variograms. The following conclusions are worth emphasizing:

1. Both microwave observations and model simulations reveal that spatial soil moisture fields exhibit approximate scale-invariance in their generalized variograms over length scales between 0.8 and $10.4 \mathrm{~km}$.

2. Analyses of the parameters characterizing the variograms of the values of microwave observations and model simulations indicate significant changes with spatial average soil water content. However, microwave observations and model simulations give contradictory results regarding the relationship between the variogram parameters which measure spatial organization and average soil water content. Following the largest $(53 \mathrm{~mm}$ averaged over the watershed) rain event during the study period, the drying process was seen to reduce the shortrange spatial correlation of the model simulations while increasing the long-range, while it increased the spatial correlation of the microwave observations.

3. Visual inspection of spatial soil moisture maps indicate that while microwave observations show river-network control on soil moisture immediately after the large rainfall event, model simulations fail to show this. This is an indication that the model simulations, though reproducing correctly the total streamflow at the outlet of the watershed, do not accurately reproduce the runoff production mechanisms. Looking at the scaling characteristics of spatial soil moisture fields can therefore serve as a more refined means of validating distributed hydrologic models, as compared to the traditional approach of just comparing the streamflow hydrographs.

Edited by: J. de Lima

Reviewed by: A. Tarquis and another anonymous referee

\section{References}

Albertson, J. D. and Montaldo, N.: Temporal Dynamics of Soil Moisture Variability: 1. Theoretical Basis, Water Resour. Res., 39(10), 1274, doi:10.1029/2002WR001616, 2003.

Allen, P. B. and Naney, J. W.: Hydrology of the Little Washita River Watershed, Oklahoma: Data and Analyses, USDA/ARS90, USDA Agricultural Research Service, Durant, OK, 74 pp., available from National Agricultural Water Quality Laboratory, Durant, OK 74702/, 1991.

Bell, K. R., Blanchard, B. J., Schmugge, T. J., and Witczak, M. W.: Analysis of surface moisture variations within large-field sites, Water Resour. Res., 16(4), 797-810, 1980.

Bertoldi, G., Rigon, R., and Over, T. M.: Impact of watershed geomorphic characteristics on the energy and water budgets, J. Hydrometeorol., 7, 389-403, 2006.

Das, N. N. and Mohanty, B. P.: Temporal dynamics of PSR-based soil moisture across spatial scales in an agricultural landscape during SMEX02: A wavelet approach, Rem. Sens. Environ., 112, 522-534, 2008.

Dubayah, R., Wood, E. F., and Lavalee, D.: Multiscaling analysis in distributed modeling and remote sensing: an application using soil moisture, in: Scale in Remote Sensing and GIS, edited by: Quattrochi, D. A. and Goodchild, M. F., Boca Raton (FL), CRC/Lewis Publishers, pp. 93-111, 1997.

Famiglietti, J. S., Devereaux, J. A., Laymon, C. A., Tsegaye, T., Houser, P. R., and Jackson, T. J., Graham, S., Rodell, M., and van Oevelen, P.: Ground-based investigation of soil moisture variability within remote sensing footprints during the Southern Great Plains 1997 (SGP97) Hydrology Experiment, Water Resour. Res., 35(6), 1839-1851, 1999.

$\mathrm{Hu}, \mathrm{Z}$., Islam, S., and Chen, Y.: Statistical characterization of remotely sensed soil moisture images, Rem. Sens. Environ., 61, 310-318, 1997.

Jackson, T. J.: Southern Great Plains 1997 (SGP97) Hydrology Experiment Plan, USDA-ARS Hydrology Laboratory, Beltsville, MD, 178 pp., available from Beltsville Agricultural Research Center, Room 104, Building 007, BARC-West, Beltsville, MD 20705, 1997.

Jackson, T. J. and LeVine, D. M.: Mapping of soil moisture using an aircraft-based passive microwave instrument: Algorithm and example, J. Hydrol., 184, 85-99, 1996.

Jackson, T. J., LeVine, D. M., Hsu, A. Y., Oldak, A., Starks, P. J., Swift, C. T., Isham, J. D., and Haken, M.: Soil moisture mapping at regional scales using microwave radiometry: the Southern Great Plains hydrology experiment, IEEE Trans. Geosci. Remote Sens., 37(5), 2136-2151, 1999. 
Jackson, T. J., Levine, D. M., Schmugge, C. T., and Schiebe, F. R.: Large area mapping of soil moisture using the ESTAR passive microwave radiometer in Washita '92, Rem. Sens. Environ., 53, 27-37, 1995.

LeVine, D. M., Griffiths, A. J., Swift, C. T., and Jackson, T. J.: ESTAR: A synthetic aperture microwave radiometer for remote sensing applications, Proc. IEEE, 82, 1787-1801, 1994.

Manfreda, S., McCabe, M. F., Fiorentino, M., Rodriguez-Iturbe, I., and Wood, E. F.: Scaling characteristics of spatial patterns of soil moisture from distributed modeling, Adv. Water Resour., 30, 2145-2150, 2007.

Mohanty, B. P., Shouse, P. J., Miller, D. A., and van Genuchten, M. T.: Soil property database: Southern Great Plains 1997 Hydrology Experiment, Water Resour. Res., 38, 1047, doi:10.1029/2000WR000076, 2002.

Nijssen, B., Lettenmaier, D. P., Liang, X., Wetzel, S. W., and Wood, E. F.: Streamflow simulation for continental-scale river basins, Water Resour. Res., 33(4), 711-724, 1997.

Njoku, E. G., Jackson, T. J., Lakshmi, V., Chan, T. K., and Nghiem, S. V.: Soil moisture retrieval from AMSR-E, IEEE Geosci. Rem. Sens., 41(2), 215-229, 2003.

Nykanen, D. K. and Foufoula-Georgiou, E.: Soil moisture variability and scale-dependency of nonlinear parameterizations in coupled land-atmosphere models, Adv. Water Resour., 24, 1143 1157, 2001.
Oldak, A., Pachepsky, Y., Jackson, T. J., and Rawls, W. J.: Statistical properties of soil moisture images revisitied, J. Hydrol., 255, 12-24, 2002.

Peters-Lidard, C. D., Pan, F., and Wood, E. F.: A re-examination of modeled and measured soil moisture spatial variability and its implications for land surface modeling, Adv. Water Resour., 24, 1069-1083, 2001.

Rawls, W., Brakensiek, D. L., and Saxton, K. E.: Estimation of soil properties, Trans. ASAE, 25(5), 1316-1326, 1982.

Rigon, R., Bertoldi, G., and Over, T. M.: GEOtop; A distributed hydrological model with coupled water and energy budgets, J. Hydromet., 7, 371-388, 2006.

Rodriguez-Iturbe, I., Vogel, C. K., Rigon, R., Entekhabi, D., Castelli, F., and Rinaldo, A.: On the spatial organization of soil moisture fields, Geophys. Res. Lett., 22(20), 2757-2760, 1995.

Silvestrin, P., Berger, M., Kerr, Y. H., and Font, J.: ESA's second earth explorer opportunity mission: the soil moisture and ocean salinity mission - SMOS, IEEE Geosc. Rem. Sens. Newsl., 118, 11-14, 2001.

Yaglom, A. M.: Correlation Theory of Stationary and Related Random Functions, vol. 1, Basic Results, Springer-Verlag, 526 pp., 1987. 